\title{
Impacto econômico da implantação das boas práticas agropecuárias relacionadas com a qualidade do leite ${ }^{1}$
}

\author{
Marcel Gomes Paixão ${ }^{2}$, Marcos Aurélio Lopes ${ }^{3}$, Sandra Maria Pinto ${ }^{4}$, Luiz Ronaldo de Abreu \\ http://dx.doi.org/10.1590/0034-737X201461050003
}

\begin{abstract}
RESUMO
Objetivou-se, neste estudo, avaliar o impacto econômico da implantação das boas práticas agropecuárias (BPA), relacionadas com a qualidade higiênica sanitária do leite. A pesquisa consistiu na simulação de nove cenários, compostos por três diferentes níveis de BPA para a melhoria da qualidade do leite (baixo, médio e alto), em três diferentes situações (somente aplicação das BPAs; aplicação das BPAs e construção da sala do leite; e aplicação das BPAs, construção da sala do leite e aquisição do tanque de expansão). O rebanho leiteiro hipotético constava de 30 vacas em lactação, com média de dez litros de leite/animal/dia, ordenhadas duas vezes ao dia, em ordenhadeira tipo "balde ao pé". A receita consistiu na média da bonificação/penalização, praticadas por dez laticínios da região sudeste, considerando-se diferentes intervalos de contagem de células somáticas (CCS) e contagem bacteriana total (CBT). A inclusão das BPAs para a melhoria da qualidade do leite, quando praticadas em seu nível máximo, mostrou-se com rápido retorno do capital investido (payback) e ótima taxa interna de retorno (TIR) apenas para aqueles pecuaristas que já possuíam a sala do leite e o tanque de expansão.
\end{abstract}

Palavras-chave: análise econômica, bovinocultura leiteira, boas práticas de fabricação, simulação.

\begin{abstract}
Economic impact of the implementation of good agricultural practices related to milk quality

The objective of this work was to evaluate the economic impact of the implementation of good agricultural practices (GAP) related to hygienic and sanitary quality of milk. The study consisted in simulating nine scenarios with three different levels of GAP for the improvement of milk quality (low, medium and high) in three different situations (application of GAP only; application of GAP and "milk room" building; application of GAP, "milk room" building and acquisition of a bulk tank). The hypothetic dairy herd had 30 lactating cows, with an average of 10 liters of milk/cow/day and milked twice a day by an automatic milking bucket. The revenues consisted of the bonus/ penalty average established by 10 dairy plants in the southeast region, considering the different ranges of somatic cell count (SCC) and total bacterial count (TBC). The inclusion of the GAP to improve milk quality, when practiced at maximum level, showed itself with rapid return on invested capital (payback) and excellent internal rate of return (IRR) only for those farmers who already had the "milk room" and the bulk tank.
\end{abstract}

Keywords: economic analysis, dairy cattle, good manufacturing practices, simulation.

\footnotetext{
Recebido para publicação em: 06/05/2013 e aprovado em 13/03/2014

${ }^{1}$ Este trabalho é parte integrante do TCC do curso de pós-graduação Lato-sensu do primeiro autor.

2ZZotecnista, Mestre. Departamento de Ciência dos Alimentos, Universidade Federal de Lavras, Caixa postal 3037, 37200-000, Lavras, Minas Gerais, Brasil. marcel.paixao@ yahoo.com.br ${ }^{3}$ Licenciado em Ciências Agrícolas, Doutor. Departamento de Medicina Veterinária, Universidade Federal de Lavras, Caixa postal 3037, 37200-000, Lavras, Minas Gerais, Brasil. malopes@dmv.ufla.br (autor para correspondência).

${ }^{4}$ Zootecnista, Pós-doutora. Departamento de Ciência dos Alimentos, Universidade Federal de Lavras, Caixa postal 3037, 37200-000, Lavras, Minas Gerais, Brasil. sandra@ dca.ufla.br ${ }^{5}$ Zootecnista, Ph.D. Departamento de Ciência dos Alimentos, Universidade Federal de Lavras, Caixa postal 3037, 37200-000, Lavras, Minas Gerais, Brasil. lrabreu@dca.ufla.br
} 


\section{INTRODUÇÃO}

O mercado está-se tornando cada vez mais exigente em relação à qualidade do leite, graças à percepção do papel exercido pelos alimentos e seus componentes sobre a saúde dos consumidores. O leite de qualidade deve apresentar composição química, microbiológica (contagem bacteriana total - CBT), organoléptica e contagem de células somáticas (CCS) que atendam aos parâmetros exigidos por lei (Ribeiro et al., 2000; Brasil, 2011).

No Brasil, a legislação vigente para os padrões de qualidade do leite é a Instrução Normativa (IN) n ${ }^{\circ} 62$, de 29 de dezembro de 2011, que complementou a normativa anterior (IN n ${ }^{\circ} 51$, de 18 de setembro de 2002) e estabeleceu novos parâmetros e datas limites para os níveis de CCS e CBT (Brasil, 2002; Brasil, 2011). Com o intuito de instituir, de forma progressiva, o pagamento diferenciado do produto de acordo com sua qualidade, as indústrias de grande porte passaram a estabelecer novos requisitos para o recebimento do leite, vinculando a remuneração à qualidade do leite fornecido (Fonseca et al., 2006). Além do pagamento de bonificações pelo leite de alta qualidade, podem ser praticadas penalizações para o leite de baixa qualidade (Álvares, 2005).

De maneira geral, a baixa qualidade do leite pode ser atribuída a deficiências no manejo, à higiene na ordenha, à sanidade da glândula mamária, à manutenção e desinfecção inadequada dos equipamentos e à refrigeração ineficiente, ou, até mesmo, inexistente (Nero et al., 2005). Por isso, cuidados higiênicos para evitar a contaminação do leite devem ter início na ordenha e seguir até o seu beneficiamento (Santana et al., 2001). Isso pode ser obtido por meio das boas práticas agropecuárias (BPA) (Embrapa, 2005).

As BPAs, na pecuária leiteira, constituem um conjunto de atividades desenvolvidas dentro da fazenda com objetivo de garantir a saúde, o bem estar e a segurança dos animais, do homem e do ambiente. Essas práticas estão associadas ao processamento de derivados lácteos seguros e de qualidade, à sustentabilidade ambiental e à possibilidade de agregação de valor, além de ser uma exigência dos consumidores e da legislação (Embrapa, 2005).

Vallin et al. (2009) verificaram redução média de $87,90 \%$ na CBT, nas propriedades com ordenha manual, e de $86,99 \%$, nas propriedades com ordenha mecânica, após a implantação das BPAs, e, em relação a CCS, a redução média foi de 33,94 e 51,85\%, respectivamente. Júnior et al. (2011) relataram que, após a implantação das BPAs, também houve melhorias na qualidade do leite dos animais, principalmente para os parâmetros de contagem padrão em placa e acidez.
Por causa do grande número de cálculos e de detalhes, exigidos para se determinar o custo de implantação das BPAs relacionadas com a melhoria da qualidade do leite, muitos produtores e técnicos desconhecem os impactos econômicos advindos das bonificações e das penalizações relativas à contagem de células somáticas e contagem bacteriana total. Raras são as pesquisas referentes ao impacto econômico da alta CCS do leite, por presença de mastite no rebanho. Em vasta revisão de literatura, não se constataram resultados de pesquisas referentes ao impacto econômico da alta CBT do leite, até o momento. A avaliação do impacto econômico da implantação das BPAs relacionadas com a qualidade higiênica sanitária do leite é assunto inédito, na literatura, e fundamental, pois, com certeza, será útil na definição de políticas referentes ao pagamento do leite por qualidade, utilizado pelas indústrias laticinistas. Além de que, as informações advindas das pesquisas serão de grande importância também para produtores rurais, acadêmicos e extensionistas, que as usarão para convencer àqueles que ainda não se conscientizaram da importância do assunto.

Considerando-se os aspectos apresentados, bem como a importância do tema, objetivou-se, com esta pesquisa, avaliar o impacto econômico da implantação das BPAs relacionadas com a qualidade higiênica sanitária do leite, visando a mostrar, aos pecuaristas, aos acadêmicos e às indústrias de laticínios, a importância dessas práticas, tanto para a qualidade do produto quanto para a rentabilidade da atividade leiteira.

\section{MATERIAL E MÉTODOS}

A pesquisa foi conduzida no Laboratório de Informática Aplicada à Produção Animal (LIA), do Departamento de Medicina Veterinária, da Universidade Federal de Lavras, por meio de simulação de dados, utilizando-se o sistema computacional "CU\$TO IQL - CUSTO DA IMPLANTAÇÃO DA QUALIDADE DO LEITE”, desenvolvido especificamente para esse fim.

O rebanho leiteiro hipotético constava de 30 vacas em lactação, com média de dez litros de leite/animal/ dia, ordenhadas duas vezes ao dia, mecanicamente, utilizando-se quatro conjuntos acoplados a dois baldes (ordenhadeira tipo "Balde ao pé"). Essa atividade era realizada por um funcionário contratado, em sala de ordenha coberta, de acordo com as especificações da IN $n^{\circ}$ 62 (Brasil, 2011). Assim, a produção anual totalizou 109.500 litros de leite/ano (30 vacas x 10 L x 365 dias).

A pesquisa consistiu na simulação de nove cenários, compostos por três diferentes níveis de inclusão das BPAs: Baixa (cenários 1; 2 e 3); média (cenários 4; 5 e 6) e alta (cenários 7; 8 e 9); em três diferentes situações (considerando-se diferenças nas aquisições de benfeito- 
rias e equipamentos: somente a aplicação das BPAs, considerando-se que o produtor possuía a sala do leite e o tanque de expansão (cenários 3; 6 e 9); aplicação das BPAs e construção da sala do leite, considerando-se que o produtor não a possuía (cenários 2; 5 e 8); e aplicação das BPAs, construção da sala do leite e aquisição do tanque de expansão, considerando-se que o produtor não possuía ambos (cenários 1; 4 e 7).

Para a classificação dos diferentes níveis de BPA, considerou-se 26 quesitos, para baixo, médio e alto nível de BPA, respectivamente, listados abaixo:

01) Intervalo de CCS (células/mL x 10³): de 401 a 600; de 201 a 400; de 0 a 200;

02) Intervalo de CBT (UFC/mL x 10³): de 401 a 600; de 201 a 400; de 0 a 200;

03) Produção de leite (relacionada com os níveis de CCS) (NMC, 1996): perda de até $8,77 \%$ de produção; perda de até $4,25 \%$ de produção; sem perda de produção;

04) Bonificação ou penalização total ( $\mathrm{R}$ /L leite): 0,$0011 ; 0,0208 ; 0,0497$

05) Uso de pré-dipping: não utiliza; utiliza diluído com $25 \%$ de água e não espera 30 segundos para secar os tetos; utiliza quantidade indicada e espera 30 segundos para secar os tetos;

06) Uso de pós-dipping: não utiliza; utiliza diluído com $25 \%$ de água; utiliza quantidade indicada;

07) Assistência técnica para equipamento de ordenha (meses): $12 ; 9 ; 6$;

08) Assistência técnica para equipamento de refrigeração (meses): não utiliza; 18; 12;

09) Treinamento do ordenhador: não utiliza; somente aulas teóricas - 2 dias; aulas teóricas e práticas - 4 dias;

10) Uso de uniformes e ferramentas de trabalho para os ordenhadores: não utiliza; utilizam, renovando o uniforme anualmente; utilizam, renovando o uniforme em 6 meses;

11) Limpeza do local de ordenha: não adequada; adequada; adequada;

12) Secagem dos tetos: não utiliza; utiliza uma folha de papel/vaca/ordenha; utiliza duas folhas de papel/vaca/ordenha;

13) Troca mangueira do leite (meses): 12; 9; 6;

14) Troca de mangueiras do vácuo (longa e curta) (meses): $24 ; 18 ; 12$;

15) Troca de conjuntos insufladores (quantidade de ordenhas): 5.000; 3.750; 2.500;

16) Uso de detergente alcalino, detergente ácido e cloro para limpeza do tanque e equipamento de ordenha:
$50 \%$ da quantidade indicada; $75 \%$ da quantidade indicada; $100 \%$ da quantidade indicada;

17) Utilização de água quente para limpeza dos equipamentos: não utiliza; utiliza, porém não controla a temperatura; utiliza na temperatura indicada;

18) Teste da caneca telada: não utiliza; utiliza, porém considera no mínimo cinco e no máximo oito jatos; utiliza, considerando apenas os três primeiros jatos;

19) Teste CMT: não utiliza; utiliza bimestralmente; utiliza quinzenalmente;

20) Utilização do sistema de "linha de ordenha": não utiliza; utiliza, considerando o volume de produção e estádio de lactação; utiliza considerando volume de produção, estádio de lactação e teste CMT;

21) Metodologia da inserção da cânula para tratamento intramamário de mastite: insere completamente no interior do teto, sem a devida higienização; insere completamente no interior do teto, com a devida higienização; insere somente o necessário para injeção do medicamento, com a devida higienização;

22) Presença de animais domésticos no local de ordenha e sala do leite: indiferença por parte do responsável; retira-os somente quando imprevisto ocorre; não permite a presença de animais;

23) Método utilizado para retirar o leite residual: pressiona o copo do conjunto de insufladores para baixo; ordenha manualmente, sem a devida higienização das mãos; ordenha manualmente, com as mãos devidamente higienizadas;

24) Análises microbiológicas da água da propriedade: realiza somente uma vez; realiza a cada 12 meses; realiza a cada 6 meses;

25) Análises físico-químicas da água da propriedade: realiza somente uma vez; realiza a cada 24 meses; realiza a cada 12 meses;

26) Sanitização do reservatório de água: não realiza; realiza a cada 12 meses; realiza a cada 6 meses.

Todos os itens listados foram considerados nas simulações, excetuando-se aqueles que necessitam de mudança de atitude por parte do ordenhador, pois foram considerados em seus treinamentos teóricos e práticos. Os preços dos produtos utilizados foram cotados no comércio de Lavras, MG, e região, bem como em sites de lojas virtuais de produtos agrícolas, de janeiro a julho de 2012, divididos em: "Material de consumo do grupo ordenha"; "Diversos"; "Benfeitorias e itens depreciáveis", "Mão de Obra", "Análises" e "Taxas".

Os materiais considerados no grupo "Material de consumo do grupo ordenha" foram: iodo $0,25 \%$ (pré- 
dipping); iodo glicerinado 0,5\% (pós- dipping); hipoclorito de sódio 9\%; detergente alcalino clorado premium; detergente ácido premium; insufladores; papel toalha; solução CMT; coador de leite; copos pré e pósdipping; raquete CMT; caneca de fundo escuro; mangueira tubo longo duplo vácuo; mangueira tubo longo (vácuo); mangueira do leite; escova para insufladores. Os gastos com insufladores, mangueiras (tubo longo duplo vácuo, vácuo e do leite), apesar de fazerem parte do equipamento de ordenha, não foram considerados como investimentos em equipamentos, pois apresentam vida útil menor que, ou igual a, um ciclo produtivo (12 meses).

Para a estimativa das quantidades de alguns itens, que se referem à BPA máxima, foram adotados os seguintes procedimentos: iodo, para pré-dipping $(0,625 \mathrm{~mL} / \mathrm{teto})$; iodo glicerinado, para pós-dipping $(1 \mathrm{~mL} / \mathrm{teto})$; hipoclorito de sódio $9 \%$ [(45 mL/ordenha realizada, para sanitização prévia) e $(88 \mathrm{~mL} /$ coleta de leite realizada, para sanitização do tanque de expansão)]; detergente alcalino clorado premium [ $(25 \mathrm{~mL} /$ ordenha, para sanitização do equipamento de ordenha) e (56 $\mathrm{ml} /$ coleta de leite realizada, para sanitização do tanque de expansão); detergente ácido premium $[(25 \mathrm{~mL} /$ limpeza semanal do equipamento de ordenha) e $(56 \mathrm{~mL} /$ coleta de leite realizada, sanitização do tanque de expansão)]; solução para teste CMT ( $2 \mathrm{~mL} /$ teto/teste). Para os demais casos e itens (média e baixa BPA), as quantidades foram aquelas especificadas nos quesitos de classificação dos diferentes níveis de BPA.

Os itens incluídos nas despesas "Diversas" foram: Vassoura; rodo; balde plástico; pano de chão (exceto para os cenários 1, 2 e 3); esponja abrasiva industrial; escova para limpeza; luvas descartáveis; avental de polietileno (exceto para os cenários 1; 2 e 3); boné branco (exceto para os cenários 1; 2 e 3); macacão branco (exceto para os cenários 1; 2 e 3); par de botas brancas (exceto para os cenários 1; 2 e 3); "cinturão da qualidade" (porta papel toalha e pré-dipping; exceto para os cenários 1; 2 e 3 ); detergente neutro e taxa de reparo e manutenção de benfeitorias e equipamentos (estimada em $2 \%$ do valor total dos itens incluídos no inventário, por ano). Assim como os itens incluídos no grupo "Material de consumo do grupo ordenha", a quantidade dos itens do grupo "Diversos" variou conforme os níveis de BPA estabelecidos no trabalho.

As benfeitorias e os itens depreciáveis foram: sala do leite, torneira e pia (cenários 1; 2; 4; 5; 7 e 8); tanque de expansão 750 litros (bacia inox), motor elétrico do tanque de expansão (750 litros) (cenários 1; 4 e 7); aquecedor de água de 4.000 Watts (cenários 4; 5; 6; 7; 8 e 9). $\mathrm{O}$ tanque de expansão foi dimensionado de acordo com a produção de leite do rebanho em quatro ordenhas consecutivas, com margem de segurança de 150 litros. Ape- sar de a sala do leite não ser uma exigência para a produção de leite cru refrigerado e, sim, para leite tipo A (IN $\mathrm{n}^{\circ} 62$-Brasil, 2011), a sua implantação auxilia a aplicação das BPAs para a qualidade do leite, e esta foi projetada com $2 \mathrm{~m} \times 2 \mathrm{~m}$ e pé direito de $2,5 \mathrm{~m}$, sendo o mínimo necessário para alojar o tanque, juntamente com pia e torneira, e considerado o valor de $\mathrm{R} \$ 700,00 / \mathrm{m}^{2}$. A vida útil da "sala do leite" foi estimada em 40 anos e o valor de sucata em $\mathrm{R} \$ 0,00$.

Os serviços utilizados nos grupos "Mão de Obra" e "Análises" foram respectivamente: assistência técnica para o equipamento de ordenha; assistência técnica para o equipamento de refrigeração (exceto para os cenários 1; 2 e 3); treinamento do ordenhador (exceto para os cenários 1; 2 e 3); diária do ordenhador substituto (exceto para os cenários $1 ; 2$ e 3); análise microbiológica da água; análise físico-química da água; análise de contagem bacteriana total do leite; análise de contagem de células somáticas do leite. Para o treinamento da mão de obra, foi considerado um valor de $\mathrm{R} \$ 0,00$, baseando-se em que diversos órgãos, como o SENAR - Serviço Nacional de Aprendizagem Rural, oferecem treinamento gratuito. Foi considerado o valor de $\mathrm{R} \$ 40,00 /$ dia, levandose em conta os dias de treinamento do ordenhador, o que corresponde ao dia de um profissional substituto. As análises de água físico-química e microbiológica, conforme a Portaria $\mathrm{n}^{\circ} 518$, de 2004 , tiveram seus preços cotados em um laboratório da região. Os gastos com análises de contagem bacteriana total e de contagem de células somáticas do leite dos tanques foram realizadas para aferir a qualidade higiênico sanitária do leite. Os valores foram cotados em um laboratório da rede brasileira de laboratórios de qualidade do leite, em Janeiro de 2012.

A taxa de poupança, que será considerada como a taxa mínima de atratividade, e o preço da energia elétrica na zona rural de Lavras, MG, foram estabelecidos em $6 \%$ ao ano e $\mathrm{R} \$ 0,22 \mathrm{~kW} / \mathrm{h}$, respectivamente. Não foram considerados os gastos com energia elétrica do equipamento de ordenha e do tanque de expansão, pois esses gastos independem da implantação ou não das BPAs.

Quanto à metodologia para estimativa do impacto econômico, consideraram-se os custos totais, os operacionais e as receitas (Lopes et al., 2012). Os itens que compõem o custo operacional efetivo de implantação das BPAs, referentes à melhoria da qualidade do leite, foram divididos em cinco grupos: "Mão de obra", "Material de consumo do grupo ordenha", "Diversas", "Análises" e "Energia". Para a determinação dos "Custos fixos", consideraram-se a construção da sala do leite e a aquisição dos equipamentos (tanque de expansão e aquecedor de água). A depreciação foi calculada pelo método linear (Hoffmann et al., 1981). Para os gastos 
com os "Custos variáveis", foram considerados os valores com "Mão de obra", "Material de consumo do grupo ordenha", "Diversos", "Análises", "Energia” e "Remuneração do capital de giro".

A receita baseou-se na bonificação ou penalização, advindas dos programas de pagamento por qualidade do leite, considerando-se os parâmetros de CCS e CBT, pois podem ser influenciados diretamente pela utilização, ou não, das BPAs para a qualidade do leite. Tanto a CCS quanto a CBT foram estratificadas, conforme a classificação por qualidade de dez empresas de laticínios, localizadas no sudeste do Brasil, em janeiro de 2012, constituindo a distinção das receitas dos cenários. A média dos valores de bonificações e penalizações, em função das diferentes faixas de CCS (x 10 $10^{3}$ células $/ \mathrm{mL}$ ) e CBT (x 10 $\mathrm{UFC} / \mathrm{mL}$ ), praticada pelas dez empresas de laticínios, localizadas no sudeste do Brasil, em janeiro de 2012, foram:

$\checkmark$ BPAALTA (cenários 7; 8 e 9): 0 a 200 células $(0,0225)$ e unidades formadoras de colônias ( $\mathrm{R} \$ 0,0272)$;

$\checkmark \quad$ BPA MÉDIA (cenários 4; 5 e 6): 201 a 400 células $(0,0113)$ e unidades formadoras de colônias $(\mathrm{R} \$ 0,0095)$;
BPA BAIXA (cenários 1; 2 e 3): 401 a 600 células $(-0,0024)$ e unidades formadoras de colônias $(\mathrm{R} \$ 0,0013)$.

A metodologia utilizada nos cálculos da margem bruta e da margem líquida foi a utilizada por Lopes et al. (2012). A rentabilidade foi calculada conforme o preconizado por Matarazzo (1997). Com o levantamento dos custos de implantação e de manutenção das diferentes BPA referentes à melhoria da qualidade do leite, procedeu-se a uma análise de viabilidade econômica, estimando-se o "Valor presente líquido" (VPL), a "Taxa interna de retorno" (TIR) e o "Payback", conforme (Figueiredo et al., 2006).

\section{RESULTADOS E DISCUSSÃO}

Os valores referentes aos investimentos e a suas respectivas depreciações, necessárias para a implantação das BPAs relacionadas com a qualidade do leite, nos diferentes cenários, são apresentados na Tabela 1. Para o cenário 3 , nenhum investimento foi realizado, pois o produtor já possuía todas as benfeitorias e equipamentos necessários. Nos cenários 6 e 9, os valores de $\mathrm{R} \$ 154,00$ foram provenientes do aquecedor de água. $\mathrm{O}$

Tabela 1. Investimentos e suas respectivas depreciações, necessários para a implantação das Boas práticas agropecuárias (BPA), relacionadas com a qualidade do leite, nas diferentes situações e cenários

Situação 1: Aplicação dos diferentes níveis de BPA, construção da sala do leite e aquisição do tanque de expansão (valores em R \$)

\begin{tabular}{lccc}
\hline Item & Cenário 1 (BPA baixa) & Cenário 4 (BPA média) & Cenário 7 (BPA alta) \\
\hline Benfeitorias & $2.800,00(8,35 \%)$ & $2.800,00(8,22 \%)$ & $2.800,00(8,22 \%)$ \\
Depreciação/ano & 70,00 & 70,00 & 70,00 \\
Equipamentos & $8.000,00(90,70 \%)$ & $8.154,00(90,85 \%)$ & $8.154,00(90,85 \%)$ \\
Depreciação/ano & 752,00 & 767,09 & 767,09 \\
Itens sala do leite & $79,00(0,94 \%)$ & $79,00(0,93 \%)$ & $79,00(0,93 \%)$ \\
Depreciação/ano & 7,90 & 7,90 & 7,90 \\
Investimento total & $10.879,00(100 \%)$ & $11.033,00(100 \%)$ & $11.033,00(100 \%)$ \\
Depreciação total/ano & 829,90 & 844,99 & 844,99
\end{tabular}

Situação 2: Aplicação dos diferentes níveis de BPA e construção da sala do leite (valores em R\$)

\begin{tabular}{lccc}
\hline Item & Cenário 2 (BPA baixa) & Cenário 5 (BPA média) & Cenário 8 (BPA alta) \\
\hline Benfeitorias & $2.800,00(89,86 \%)$ & $2.800,00(76,29 \%)$ & $2.800,00(76,29 \%)$ \\
Depreciação/ano & 70,00 & 70,00 & 70,00 \\
Equipamentos & $0,00(0,00 \%)$ & $154,00(15,10 \%)$ & $154,00(15,10 \%)$ \\
Depreciação/ano & 0,00 & 15,09 & 15,09 \\
Itens sala do leite & $79,00(10,14 \%)$ & $79,00(8,61 \%)$ & $79,00(8,61 \%)$ \\
Depreciação/ano & 7,90 & 7,90 & 7,90 \\
Investimento total & $2.879,00(100 \%)$ & $3.033,00(100 \%)$ & $3.033,00(100 \%)$ \\
Depreciação total/ano & $829,90^{*}$ & $844,99 *$ & $844,99^{*}$ \\
\hline
\end{tabular}

Situação 3: Somente aplicação dos diferentes níveis de BPA (valores em R\$)

\begin{tabular}{lccc}
\hline Item & Cenário 3 (BPA baixa) & Cenário 6 (BPA média) & Cenário 9 (BPA alta) \\
\hline Equipamentos & $0,00(0,00 \%)$ & $154,00(100 \%)$ & $154,00(100 \%)$ \\
Depreciação/ano & 0,00 & 15,09 & 15,09 \\
Investimento total & $0,00(0,00 \%)$ & $154,00(100 \%)$ & $154,00(100 \%)$ \\
Depreciação total/ano & $829,90^{*}$ & $844,99 *$ & $844,99^{*}$ \\
\hline
\end{tabular}

*Considerando a depreciação dos equipamentos que o proprietário já possuía.

Rev. Ceres, Viçosa, v. 61, n.5, p. 612-621, set/out, 2014 
tanque de expansão, quando adquirido, representou $90 \%$ do valor total dos inventários. Em estudo feito por Clemente (2009), analisando os custos necessários para adequação à $\mathrm{IN} \mathrm{n}^{\circ} 51$ de 2002, verificou-se que o tanque de expansão foi o que mais impactou o custo fixo de implantação, em 63,16 \% das propriedades estudadas. Nos cenários em que somente a sala do leite foi implantada, os investimentos em benfeitorias variaram de $\mathrm{R} \$ 2.879,00$ (cenário 2) a $\mathrm{R} \$ 3.033,00$ (cenários 5 e 8). A diferença deveu-se à aquisição do aquecedor de água. Segundo Hardoim (2008), é importante dispor de um sistema de aquecimento de água para a sala de ordenha e a sala de leite, para a limpeza.

$\mathrm{Na}$ Tabela 2 verificam-se as despesas operacionais efetivas anuais, necessárias para a implantação dos diferentes níveis de BPA relacionadas com a melhoria da qualidade do leite, divididas em grupos e itens com maiores representatividades. Em todos os cenários, o grupo mais representativo foi o "Material de consumo do grupo ordenha”, o que correspondeu a soma dos gas- tos com pré e pós - dipping, limpeza do tanque de expansão e do sistema de ordenha, substituição de insufladores e mangueiras, uso do papel toalha, teste CMT, coador de leite, caneca de fundo preto e escova para insufladores (Tabela 2).

Em "Material de consumo do grupo ordenha", em todos os cenários, o item "insufladores" foi o mais oneroso (Tabela 2). A substituição dos insufladores é importante, pois, com o tempo, ressecam-se e, segundo Coentrão et al. (2008), criam-se microrrachaduras, com posteriores rachaduras maiores, possibilitando a formação de pontos que acumulam leite, dificultando a adesão ao teto, aumentando a contaminação por causa da taxa de queda, ocasionada pela entrada de ar e diminuição do vácuo do sistema.

O gasto com iodo glicerinado para pós-dipping foi o segundo item mais representativo do grupo "Material de consumo do grupo ordenha", para os casos de média e alta BPA, e representaram 24,1 e $21,7 \%$ do total dos gastos anuais deste grupo, respectivamente (Tabela 2).

Tabela 2. Despesas operacionais efetivas anuais necessárias para a implantação dos diferentes níveis de Boas práticas agropecuárias (BPA) relacionadas com a melhoria da qualidade do leite, divididas em grupos e os itens com maiores representatividades

\begin{tabular}{|c|c|c|c|c|}
\hline \multirow{2}{*}{ Grupo } & \multirow[t]{2}{*}{$\begin{array}{l}\text { Itens com maiores } \\
\text { representatividades }\end{array}$} & \multicolumn{3}{|c|}{$\begin{array}{c}\text { Cenários } \\
\text { Despesas }(\mathbf{R} \$) / \text { ano }\end{array}$} \\
\hline & & 1; 2 e 3 (BPA baixa) & 4; 5 e 6 (BPA média) & 7; 8 e 9 (BPA alta) \\
\hline \multirow{4}{*}{$\begin{array}{l}\text { Material de consumo } \\
\text { do grupo ordenha }\end{array}$} & Insufladores & $404,80(60,6 \%)$ & $642,40(31,6 \%)$ & $963,60(32,0 \%)$ \\
\hline & Iodo pós- dipping & N.U. & $488,81(24,1 \%)$ & $651,74(21,7 \%)$ \\
\hline & Total do grupo & $668,51(100 \%)$ & $2.031,77(100 \%)$ & $3.008,29(100 \%)$ \\
\hline & $\%$ do Total & $49,1 \%$ & $58,7 \%$ & $58,4 \%$ \\
\hline \multirow{4}{*}{ Diversos } & $\begin{array}{c}\text { Reparo/manutenção de } \\
\text { benfeitorias e } \\
\text { equipamentos }\end{array}$ & $217,58(56,8 \%)$ & $220,66(33,5 \%)$ & $220,66(26,8 \%)$ \\
\hline & Macacão branco & N.U. & $100,00(16,0 \%)$ & $200,00(24,3 \%)$ \\
\hline & Total do grupo & $383,33(100 \%)$ & $658,41(100 \%)$ & $822,41(100 \%)$ \\
\hline & $\%$ do Total & $28,2 \%$ & $19 \%$ & $16,0 \%$ \\
\hline \multirow{4}{*}{ Análises } & Água (físico-química) & $* 92,20(37,0 \%)$ & $92,20(37,0 \%)$ & $92,20(27,6 \%)$ \\
\hline & Água (microbiológica) & $* 85,00(34,1 \%)$ & $85,00(34,1 \%)$ & $170,00(50,9 \%)$ \\
\hline & Total do grupo & $249,20(100 \%)$ & $249,20(100 \%)$ & $334,20(100 \%)$ \\
\hline & $\%$ do Total & $18,3 \%$ & $7,2 \%$ & $6,5 \%$ \\
\hline \multirow{3}{*}{ Energia } & Aquecedor de água & N.U. & $321,20(100 \%)$ & $642,40(100 \%)$ \\
\hline & Total do grupo & $0,0 \%$ & $100,0 \%$ & $100,0 \%$ \\
\hline & $\%$ do Total & $0,0 \%$ & $9,3 \%$ & $12,5 \%$ \\
\hline \multirow{4}{*}{ Mão de obra } & $\begin{array}{c}\text { Assistência do } \\
\text { equipamento de ordenha }\end{array}$ & $60,00(100 \%)$ & $79,98(40,00 \%)$ & $160,00(47,1 \%)$ \\
\hline & $\begin{array}{l}\text { Diárias do ordenhador } \\
\text { substituto }\end{array}$ & N.U. & $80,00(40,01 \%)$ & $120,00(35,3 \%)$ \\
\hline & Total do grupo & $60,00(100 \%)$ & $199,94(100 \%)$ & $340,00(100 \%)$ \\
\hline & $\%$ do Total & $4,4 \%$ & $5,8 \%$ & $6,6 \%$ \\
\hline TOTAL & & $1.361,04(100 \%)$ & $3.460,52(100 \%)$ & $5.147,30(100 \%)$ \\
\hline
\end{tabular}

N.U.: Não utiliza; *Realizou apenas no primeiro ano de implantação do projeto. 
De acordo com Allore et al. (1998) e Berry \& Hillerton (2002), a imersão dos tetos em solução de iodo glicerinado após a ordenha contribui para a redução e controle dos casos de mastites.

O grupo "Diversos" foi o que apresentou a segunda maior representatividade nas despesas operacionais efetivas, em todos os cenários. Os gastos com "reparos e manutenção de benfeitorias e equipamentos" foi o item mais representativo nesse grupo (Tabela 2).

O grupo "Análises" apresentou terceira, quarta e quinta maiores representatividades, respectivamente para "baixa", "média" e "alta" BPA, sendo que as análises de qualidade de água (microbiológicas e físico-químicas) foram os itens com maiores representatividades nesse grupo (Tabela 2). De acordo com Philpot \& Nickerson (1991), a qualidade da água é de grande importância para a higienização dos utensílios e equipamentos de ordenha, tanto do ponto de vista físico-químico quanto do microbiológico.

Os gastos com "Mão de Obra" foram os de menor impacto, para os cenários de "baixa" e "média" BPA, e o quarto (penúltimo) para os cenários de "alta" BPA. Em todos os cenários, a "assistência técnica do equipamento de ordenha" teve uma grande representatividade (Tabela 2) e, para os de "média" e "alta" BPA, as "diárias do ordenhador substituto" também foram representativas. Apesar de ter um custo relativamente baixo, os reflexos do treinamento do ordenhador e a inclusão correta das BPAs são os itens que apresentam maior impacto na qualidade do leite. A manutenção do equipamento de ordenha e o treinamento do ordenhador são pontos chave para o controle de CBT do leite do tanque e, indiretamente, para a CCS, pois a queda das borrachas insufladores, por falta de manutenção do equipamento, possibilita a entrada de sujidades do ambiente para o leite e focos de contaminação de mastite, no equipamento (Coentrão et al. 2008; Souza et al., 2009).

A análise de rentabilidade da implantação dos diferentes níveis de BPA referentes à qualidade do leite, nos diferentes cenários, pode ser observada na Tabela 3. Para os cenários de baixa BPA, o produtor estaria descapitalizando$\mathrm{se}$, analisando-se tanto a metodologia de custo operacional total (COT) quanto a metodologia de custo total (CT). Para os cenários de média BPA, a bonificação de $\mathrm{R} \$ 0,0208 / \mathrm{L}$ foi insuficiente para cobrir os custos operacionais efetivos (COE) e, os valores "margem bruta", "margem líquida" e "resultado" ficaram próximos aos das BPAs em seu nível baixo, evidenciando, portanto, que esse nível de BPA (médio), apesar do maior investimento e atenção por parte do produtor, não obteve o retorno financeiro esperado. Para os cenários de alta BPA, as receitas das bonificações $(0,0497 \mathrm{R} \$ / \mathrm{L})$ foram superiores aos valores de COE $(0,0470 \mathrm{R} \$ / \mathrm{L})$ e dos custos variáveis (CV) $(0,0486 \mathrm{R} \$ /$
$\mathrm{L})$, porém inferiores aos $\mathrm{CT}(0,0517 \mathrm{R} \$ / \mathrm{L})$ e COT $(0,0565$ $\mathrm{R} \$ / \mathrm{L}$ ) (Tabela 3), permitindo, assim, a manutenção da atividade apenas no curto e médio prazos, mas com a inviabilidade econômica, por causa da depreciação total e dos custos de oportunidade (remunerações do capital investido) (metodologia CT). Verifica-se que a aplicação das BPAs em seu nível máximo, apesar de não custear a implantação, mostrou-se com maior viabilidade econômica, quando comparada com as demais implantações de BPA.

Alguns indicadores econômicos (payback - tempo de retorno do capital investido), valor presente líquido (VPL) e taxa interna de retorno (TIR), para os cenários estudados, foram estimados (Tabela 4). Verifica-se que somente foi possível ser estimado o payback quando implantadas as BPAs em seu nível máximo. Para o cenário 3, o payback foi considerado zero, pois nenhum investimento foi realizado. Para os VPLs, somente no cenário 9 ele foi positivo, considerando-se o tempo e a taxa proposta (6\% ao ano; 10 anos). Para o valor da TIR, tem-se que, em todos os cenários de baixa e média BPAs foram negativos, com valores maiores para os cenários de alta BPA. O projeto será financeiramente viável quando, segundo Nishi et al. (2005), a TIR for maior que a taxa mínima de atratividade. Assim, o cenário 9 foi o único que apresentou TIR superior à taxa mínima de atratividade (taxa de poupança de 6\% ao ano). Nesse cenário, cujo produtor já possuía o tanque e a sala do leite, e que teve um baixo investimento em equipamentos ( $\mathrm{R} \$ 154,00)$, a implantação das BPAs em seu nível máximo apresentou um rápido payback (aproximadamente nove meses e meio) e alta TIR (121,56\%).

Simulando-se o cenário 7 (BPA alta, com aquisição de tanque de expansão e sala do leite), porém com uma bonificação total para CCS e CBT de R $\$ 0,062 / \mathrm{L}$ de leite e não mais $\mathrm{R} \$ 0,0497 / \mathrm{L}$, tem-se os seguintes indicadores de rentabilidade: Payback de 6,87 anos; VPL: R\$753,63; TIR 7,4 \%, viabilizando-se, portanto, o projeto. Na mesma simulação, respectivamente, para os cenários 8 e 9, tem-se: Payback: 1,97 e 0,1 anos; VPL: R \$ 8.753,63 e R \$11.632,63; e TIR: 50,82 e $959,12 \%$.

Nota-se, portanto, que o aumento de $\mathrm{R} \$ 0,0123 / \mathrm{L}$ de leite, em média, pago ao produtor pelas bonificações, foi a diferença entre o sucesso e o fracasso da implantação das BPAs em seu nível alto, juntamente com os investimentos em sala do leite que, apesar de não serem exigidos pela legislação vigente para o leite cru refrigerado, são pontos críticos para a melhoria da qualidade do leite. Das dez empresas consideradas nesta pesquisa, para estabelecer a média da bonificação total máxima para CCS e CBT de R \$0,0497/L, $30 \%$ 
Tabela 3. Resumo da análise de rentabilidade da implantação dos diferentes níveis de BPA em diferentes cenários, em R \$/ano e R \$/L de leite

\begin{tabular}{|c|c|c|c|c|c|c|c|c|c|}
\hline \multirow{2}{*}{ Especificação } & \multicolumn{9}{|c|}{ Cenários } \\
\hline & 1 & 2 & 3 & 4 & 5 & 6 & 7 & 8 & 9 \\
\hline \multirow[t]{2}{*}{ Receita } & $-109,89$ & $-109,89$ & $-109,89$ & $2.180,80$ & $2.180,80$ & $2.180,80$ & $5.442,15$ & $5.442,15$ & $5.442,15$ \\
\hline & $-0,0011$ & $-0,0011$ & $-0,0011$ & 0,0208 & 0,0208 & 0,0208 & 0,0497 & 0,0497 & 0,0497 \\
\hline \multirow[t]{2}{*}{$\mathrm{COE}$} & $1.361,04$ & $1.361,04$ & $1.361,04$ & $3.460,52$ & $3.460,52$ & $3.460,52$ & $5.147,30$ & $5.147,30$ & $5.147,30$ \\
\hline & 0,0136 & 0,0136 & 0,0136 & 0,0330 & 0,0330 & 0,0330 & 0,0470 & 0,0470 & 0,0470 \\
\hline \multirow[t]{2}{*}{ *Depreciação } & 829,90 & 829,90 & 829,90 & 844,99 & 844,99 & 844,99 & 844,99 & 844,99 & 844,99 \\
\hline & 0,0083 & 0,0083 & 0,0083 & 0,0081 & 0,0081 & 0,0081 & 0,0077 & 0,0077 & 0,0077 \\
\hline \multirow[t]{2}{*}{ COT } & $2.190,94$ & $2.190,94$ & $2.190,94$ & $4.305,51$ & $4.305,51$ & $4.305,51$ & $5.658,09$ & $5.658,09$ & $5.658,09$ \\
\hline & 0,0219 & 0,0219 & 0,0219 & 0,0411 & 0,0411 & 0,0411 & 0,0517 & 0,0517 & 0,0517 \\
\hline \multirow[t]{2}{*}{$\mathrm{CF}$} & $1.482,64$ & $1.020,64$ & 829,90 & $1.506,97$ & $1.026,97$ & 854,23 & $1.506,97$ & $1.026,97$ & 854,23 \\
\hline & 0,0148 & 0,01 & 0,0083 & 0,0144 & 0,0098 & 0,0081 & 0,0138 & 0,0094 & 0,0078 \\
\hline \multirow[t]{2}{*}{$\mathrm{CV}$} & $1.426,77$ & $1.426,77$ & $1.426,77$ & $3.589,69$ & $3.589,69$ & $3.589,69$ & $5.327,07$ & $5.327,07$ & $5.327,07$ \\
\hline & 0,0143 & 0,0143 & 0,0143 & 0,0342 & 0,0342 & 0,0342 & 0,0486 & 0,0486 & 0,0486 \\
\hline \multirow[t]{2}{*}{$\mathrm{CT}$} & $2.909,41$ & $2.429,41$ & $2.256,67$ & $5.096,66$ & $4.616,66$ & $4.443,92$ & $6.834,04$ & $6.354,04$ & $6.181,30$ \\
\hline & 0,0291 & 0,0243 & 0,0226 & 0,0486 & 0,0440 & 0,0424 & 0,0624 & 0,0580 & 0,0565 \\
\hline \multirow[t]{2}{*}{ Margem bruta } & $-1.470,93$ & $-1.470,93$ & $-1.470,93$ & $-1.279,72$ & $-1.279,72$ & $-1.279,72$ & 294,85 & 294,85 & 294,85 \\
\hline & $-0,0147$ & $-0,0147$ & $-0,0147$ & $-0,0122$ & $-0,0122$ & $-0,0122$ & 0,0027 & 0,0027 & 0,0027 \\
\hline \multirow[t]{2}{*}{ Margem líquida } & $-2.300,83$ & $-2.300,83$ & $-2.300,83$ & $-2.124,71$ & $-2.124,71$ & $-2.124,71$ & $-215,94$ & $-215,94$ & $-215,94$ \\
\hline & $-0,0230$ & $-0,0230$ & $-0,0230$ & $-0,0203$ & $-0,0203$ & $-0,0203$ & $-0,0020$ & $-0,0020$ & $-0,0020$ \\
\hline \multirow[t]{2}{*}{ Resultado } & $-3.019,29$ & $-2.539,29$ & $-2.366,55$ & $-2.915,86$ & $-2.435,85$ & $-2.263,11$ & $-1.391,89$ & $-911,89$ & $-739,15$ \\
\hline & $-0,0302$ & $-0,0254$ & $-0,0237$ & $-0,0278$ & $-0,0232$ & $-0,0216$ & $-0,0127$ & $-0,0083$ & $-0,0068$ \\
\hline
\end{tabular}

COE: Custo operacional efetivo; COT: Custo operacional total; CF: Custo fixo; CV: Custo variável; CT: Custo total (CF + CV); Margem bruta: (Receita - COE); Margem líquida: (Receita - COT); Resultado: (Receita - CT) 
Tabela 4. Estimativa do Payback, VPL (Valor presente líquido) e TIR (Taxa interna de retorno) referentes aos investimentos necessários para a implantação dos diferentes níveis de BPA (Boas práticas agropecuárias) relacionadas com a melhoria da qualidade do leite, em diferentes cenários

\begin{tabular}{lccc}
\hline Cenários & Payback (anos) & VPL $(\mathbf{R} \$)$ & TIR $(\boldsymbol{\%})$ \\
\hline 1 & $*$ & $-21.051,87$ & Menor que - 100 \\
2 & $*$ & $-13.051,87$ & Menor que -100 \\
3 & $*$ & $-10.172,87$ & Menor que -100 \\
4 & $*$ & $-20.889,17$ & Menor que -100 \\
5 & $*$ & $-12.889,17$ & Menor que -100 \\
6 & $*$ & $-10.010,17$ & Menor que -100 \\
7 & $*$ & $-9.159,30$ & $-19,80$ \\
8 & $*$ & $-1.159,30$ & $-2,65$ \\
9 & 0,79 & $1.719,70$ & 121,56 \\
$7 * *$ & 6,87 & 753,63 & 7,4 \\
$8^{* *}$ & 1,97 & $8.753,63$ & 50,82 \\
$9 * *$ & 0,1 & $11.632,63$ & 959,12 \\
\hline
\end{tabular}

*Não foi possível ser estimado, pois o tempo de retorno do capital investido foi superior ao tempo considerado como horizonte do projeto (10 anos). **Cenários simulados com uma bonificação total de R \$0,062/L, para os níveis mínimos de CCS e CBT das análises (d" 200.000 células $/ \mathrm{mL} ; \mathrm{UFC} / \mathrm{mL}$ ).

bonificavam com $\mathrm{R} \$ 0,062 / \mathrm{L}$, ou mais, os produtores que alcançavam os níveis mínimos de CCS e CBT. Assim, para os pecuaristas que vendiam o leite para essas empresas e que já possuíam tanques de expansão e sala do leite, a implantação das BPAs em seu nível alto seria viável economicamente.

\section{CONCLUSÕES}

A inclusão das "Boas Práticas Agropecuárias" para a melhoria da qualidade do leite, quando praticadas em seu nível máximo, mostrou-se com rápido retorno do capital investido (payback) e ótima taxa interna de retorno (TIR). Porém, a aquisição do tanque de expansão e, ou, da sala do leite, mesmo com a bonificação máxima, considerando-se a média das empresas, não foi suficiente para viabilizar economicamente a implantação do projeto. A "Margem líquida" (Receita - COT) e o Resultado" (Receita - CT) da implantação das BPA não apresentaram viabilidade econômica em todos os casos analisados, com as devidas bonificações. Cabe aos pecuaristas e às indústrias lidarem com essa situação, seja por melhor remuneração do produto, seja por meio de contratos de compra e venda de leite in natura, prática ainda pouco difundida no Brasil.

\section{REFERENCIAS}

Allore HG, Erb HN, Schruben LW \& Oltenacu PA (1998) A simulation of strategies to lower bulk milk tank somatic cell count below 500,000 per mililiter. Journal of Dairy Science, 81:694-702.

Álvares JG (2005) Pagamento do leite por sólidos. In: Visão técnica e econômica da produção leiteira, Piracicaba. Anais, FEALQ. p.129-140.

Berry EA \& Hillerton JE (2002) The effect of selective dry cow treatment on new intramammary infections. Journal of Dairy Science, $85: 112-121$
Brasil (2002) Instrução Normativa n ${ }^{\circ} 51$, de 18 de setembro de 2002 Regulamentos Técnicos de Produção, Identidade e Qualidade do Leite tipo A, do Leite tipo B, do Leite tipo C, do Leite Pasteurizado e do Leite Cru Refrigerado e o Regulamento Técnico da Coleta de Leite Cru Refrigerado e seu Transporte a Granel. Diário Oficial da União, Brasília.

Brasil (2011) Instrução normativa n ${ }^{\circ}$ 62, de 29 de dezembro de 2011 Regulamento Técnico de Produção, Identidade e Qualidade do Leite tipo A, Leite Cru Refrigerado, Leite Pasteurizado, Leite Cru Refrigerado e seu Transporte a Granel. Diário Oficial da União, Brasília.

Clemente MG (2009) Custos para a adequação à Instrução Normativa 51 por pecuaristas de leite no sul de Minas Gerais: estudo multicasos. Tese de doutorado. Universidade Federal de Lavras, Lavras. 75p.

Coentrão CM, Souza GN, Brito JRF, Paiva e Brito MAV \& Lilenbaum W (2008) Fatores de risco para mastite subclínica em vacas leiteiras. Arquivo Brasileiro de Medicina Veterinária e Zootecnia, 60:283-288.

Embrapa (2005) Boas práticas agrícolas para produção de alimentos seguros no campo- elaboração de manual de boas práticas agropecuárias na produção leiteira. Brasília, PAS/EMBRAPA. 26p. (Manual técnico).

Figueiredo AM, Dos Santos PA, Santolin R \& Reis BS (2006) Integração na criação de frangos de corte na microrregião de Viçosa - MG: viabilidade econômica e análise de risco. Revista de Economia e Sociologia Rural, 44:713-730.

Fonseca LM, Rodrigues R, Cerqueira MMOP, Leite MO, Souza MR \& Penna CFAM (2006) Situação da qualidade do leite cru em Minas Gerais. In: Mesquita AJ, Dürr JW \& Coelho KO (Eds.) Perspectivas e avanços da qualidade do leite no Brasil. Goiânia, Talento. p.23-37.

Hardoim PC (2008) Instalações para gado de leite. $1^{\text {a }}$ ed. Lavras, Editora UFLA. 98p.

Hoffmann R, Engler JJC \& Serrano O (1981) Administração da empresa agrícola. $3^{\mathrm{a}}$ ed. São Paulo, Pioneira. 325p.

Júnior BRCL, Oliveira PM, Martins ML, Pinto CLO, Martins EMF \& Souza GH (2011) Aplicação das boas práticas agropecuárias no processo de ordenha em uma propriedade rural do município de Rio Pomba, Minas Gerais. Revista do Instituto de Laticínios "Cândido Tostes", 380:31-39.

Lopes MA, dos Santos G \& Carvalho FM (2012) Comparativo de indicadores econômicos da atividade leiteira de sistemas intensivos de produção de leite no Estado de Minas Gerais. Revista Ceres, 59:458-465. 
Matarazzo DC (1997) Análise financeira de balanços. $4^{a}$ ed. São Paulo. Atlas. 463p

National Mastitis Council - NMC (1996) Current concepts of bovine mastitis. $4^{\mathrm{a} e d .}$ Madison, The National Mastitis Council. 64p.

Nero LA, Mattos MR, Beloti V, Barros MA, Pinto PAN, Andrade NJ, Silva NJ \& Franco DGM (2005) Leite cru de quatro regiões leiteiras brasileiras: perspectivas de atendimento dos requisitos microbiológicos estabelecidos pela Instrução Normativa 51. Ciência e Tecnologia de Alimentos, 25:191-195.

Nishi MH, Jacovine LAG, Silva ML, Valverde SR, Nogueira HP \& Alvarenga AP (2005) Influência dos créditos de carbono na viabilidade financeira de três projetos florestais. Sociedade de Investigações Florestais, 29:263-270.

Philpot WN \& Nickerson SC (1991) Mastitis: Counter Attack. A strategy to combat mastitis. Illinois, Babson Brothers Co. 150p.
Ribeiro MER, Stumpf Júnior W \& Buss H (2000) Qualidade de leite. In: Bitencourt D, Pegoraro LMC \& Gomes JF. Sistemas de pecuária de leite: Uma visão na região de Clima Temperado. Pelotas. Anais, Embrapa Clima Temperado. p.175-195.

Santana EHW, Beloti V, Barros MAF, Moraes LB, Gusmão VV \& Pereira MS (2001) Contaminação do leite em diferentes pontos do processo de produção: microrganismos aeróbios mesófilos e psicrotróficos. Semina: Ciências Agrárias, 22:145-154.

Souza GN, Brito JRF, Moreira EC, Brito MAVP \& Silva MVGB (2009) Variação da contagem de células somáticas em vacas leiteiras de acordo com patógenos da mastite. Arquivo Brasileiro de Medicina Veterinária e Zootecnia, 61:1015-1020.

Vallin VM, Beloti V, Battaglini APP, Tamanini R, Fagnani R, Angela HL \& Silva LCC (2009) Melhoria da qualidade do leite a partir da implantação de boas práticas de higiene na ordenha em 19 municípios da região central do Paraná. Semina: Ciências Agrárias, 30:181-188. 